\section{Regards sur l'économie allemande}

Bulletin économique du CIRAC

$96 \mid 2010$

Varia

\title{
Sciences sociales : Prof. E. Noelle-Neumann (1916-2010)
}

Isabelle Bourgeois

\section{(2) OpenEdition}

1 Journals

Édition électronique

URL : https://journals.openedition.org/rea/4091

DOI : 10.4000/rea.4091

ISBN : 978-2-8218-0888-1

ISSN : 1965-0787

\section{Éditeur}

CIRAC

Édition imprimée

Date de publication : 1 mai 2010

Pagination : 39

ISSN : 1156-8992

\section{Référence électronique}

Isabelle Bourgeois, «Sciences sociales : Prof. E. Noelle-Neumann (1916-2010) », Regards sur

l'économie allemande [En ligne], 96 | mai 2010, mis en ligne le 01 mai 2012, consulté le 28 juin 2022.

URL : http://journals.openedition.org/rea/4091 ; DOI : https://doi.org/10.4000/rea.4091 


\section{Actualité économique}

\section{O SCIENCES SOCIALES : Prof. E. Noelle-Neumann (1916-2010)}

La "Grande Dame de la démoscopie allemande », comme la presse surnomme le Prof. Elisabeth Noelle-Neumann, s'est éteinte le 25 mars 2010 à l'âge de 93 ans. Fondatrice de l'Institut für Demoskopie d'Allensbach (IfD ; créé le 8 mai 1947), elle doit sa réputation dans l'espace public à ses sondages électoraux, souvent vérifiés, et sa notoriété scientifique à ses travaux fondamentaux en sciences sociales. Praticienne et théoricienne, elle aimait se laisser guider par ce qu'elle appelait « le principe de la surprise ", décrivant ainsi sa démarche profondément inductive : " un sondeur apprend vite à se méfier de ce qui a l'apparence de l'évidence, et à rester au contraire ouvert aux résultats imprévus; car ce sont eux qui font progresser la connaissance dans les sciences sociales puisqu'ils attirent l'attention de l'observateur sur des relations qui n'étaient jusque-là pas prises en considération » (F.A.Z., 30-12-2006).

Née en 1916 à Berlin, elle mène des études de philosophie, d'histoire, de sciences de la communication et d'américanistique, avant d'entreprendre en 1938 un tour du monde. Aux Etats-Unis, elle découvre les travaux de George Gallup sur les sondages. Elle entame un doctorat sur ceux-ci, sous la direction d'Emil Dovifat - le 'Pape' du journalisme allemand. "En réalité, je ne voulais pas devenir une scientifique, mais une journaliste », se souvient-elle dans un entretien au quotidien F.A.Z. (26-12-2006).

C'est en tant que journaliste qu'elle commence sa carrière. De retour en Allemagne, elle travaille à l'hebdomadaire Das Reich où elle est licenciée en 1942 pour refus de servir la propagande officielle, puis entre en 1943 au quotidien libéral Frankfurter Zeitung (modèle du futur F.A.Z.), interdit la même année par Hitler. En 1947, elle fonde l'IfD; la réalisation de sondages pour comprendre opinions et valeurs des Allemands est fondamentale pour reconstruire la démocratie dans la future RFA. L'institut travaille avec le chancelier Adenauer (" il avait l'habitude de gouverner contre l'opinion publique » et " utilisait la démoscopie comme un navigateur une carte ", confie-t-elle dans le même entretien) puis avec ses successeurs. Et elle parvient à persuader la presse que les sondages relèvent de l'information ; depuis 1978, l'IfD publie une analyse mensuelle dans le F.A.Z. (Allensbacher Analyse).

En 1964, E. Noelle-Neumann est nommée à l'Université de Mayence sur une chaire de Publizistik (mariage entre journalisme et sciences de la communication, considérés comme indissociables en Allemagne). Elle y fonde (et dirige jusqu'en 1983) l'Institut für Publizistik qui est aujourd'hui le centre de recherche le plus réputé d'Allemagne en sciences sociales appliquées à la communication.

Interdisciplinarité et curiosité foncière (le propre à la fois du journaliste et du scientifique) sont le moteur dune permanente interaction entre réflexion méthodologique et pensée théorique qui amène $\mathrm{E}$. Noelle-Neumann à définir " la double nature de l'être social » : le libre arbitre qu'a tout individu (dans l'approche des juristes, notamment constitutionnalistes) trouve ses limites dans l'interaction complexe entre opinion publique et mass médias (recherche en communication et en psychologie sociale). Et dans le prolongement, mais à partir d'une expérience pratique qui en fut le déclencheur, elle élabore en 1972 sa théorie de la "spirale du silence » qui intègre le rôle joué par les médias dans l'évolution de l'opinion publique. "Les êtres humains ne veulent pas s'isoler, ils passent leur temps à observer leur entourage... Celui qui constate que son opinion se répand se sent conforté et n'hésite plus à prendre la parole en public..., celui qui constate que son opinion perd du terrain va préférer se taire ». Comme, dans l'espace public, le premier groupe semble plus important que le second, "...il s'ensuit une illusion d'optique quant à la réalité des rapports de force » qui fait que le second groupe finit par être réduit au silence et que, parfois, une opinion disparaît (Noelle-Neumann, 2000 ; voir REA 80/07).

Fidèle au « double engagement » (Paul Lazarsfeld) qui lie les sciences sociales vis-àvis de la pratique (commanditaires, médias, monde politique) et de la théorie (recherche fondamentale), et pour garantir la continuité de ces travaux, elle crée en 1996 la fondation Stiftung Demoskopie Allensbach, en charge de la recherche fondamentale et financée par les activités de l'IfD dont elle est propriétaire. (IB)
La « Grande Dame de la démoscopie allemande »

Du journalisme...

... à la science

2 théories fondamentales : "la double nature de l'être social " et " la spirale du silence » 